\title{
High diagnostic yield of endobronchial ultrasound-guided transbronchial needle aspiration (EBUS-TBNA) in the diagnosis of adolescent pulmonary tuberculosis
}

Anne Geweniger ${ }^{1 \dagger}$, Ales Janda ${ }^{1,2+}$, Kristin Eder ${ }^{1}$, Roland Fressle ${ }^{3}$, Cecil Varna Kannan ${ }^{4}$, Hubert Fahnenstich ${ }^{4}$, Mirjam Elze ${ }^{5}$, Christoph Müller ${ }^{1}$, Philipp Henneke ${ }^{1,6}$, Markus Hufnagel $^{1}$ and Roland Elling ${ }^{1,6,7^{*}}$ (D)

\begin{abstract}
Background: The microbiological diagnosis of pulmonary tuberculosis ( $\mathrm{Tb}$ ) in a pediatric population is hampered by both low pathogen burden and noncompliance with sputum sampling. Although endobronchial ultrasoundguided transbronchial needle aspiration (EBUS-TBNA) has been found useful for the evaluation of mediastinal pathologies in adults, for children, sparse data are available. Here, we have evaluated EBUS-TBNA as a diagnostic procedure in children and adolescents with suspected pulmonary Tb.
\end{abstract}

Methods: In this retrospective analysis, we reviewed the charts of unaccompanied refugee minors (URM) who were admitted between January 2016 and July 2018 and who, during their initial medical screening upon arrival in Germany, were found to have abnormal radiological pulmonary and mediastinal findings and/or immunological results indicative of Tb. For each patient, basic sociodemographic data, clinical features and data on diagnostic procedures performed were assessed. These included imaging, immunodiagnostic tests and microbiological data derived from sputum, bronchoalveolar lavage, EBUS-TBNA, bronchoscopy and pleural fluid sampling. All patients who underwent invasive sampling procedures were included in the study.

Results: Out of 42 URM with suspected Tb, 34 fulfilled the study's inclusion criteria. Ages ranged from 14 to 17 years. All were of African origin, with 70.0\% coming from Somalia, Eritrea and Ethiopia. Among the 21 patients for whom EBUS-TBNA was performed, the diagnostic yield was high: $66.7 \%$ positive results (MTb detected either by acid-fast stain, culture or PCR in 4.8, 42.9 and $61.9 \%$ of samples, respectively). Multidrug-resistant MTb was found in two patients from Somalia. No complications were associated with the procedure. Overall, pulmonary Tb was diagnosed in 29 patients (85.3\%), miliary Tb in two patients (5.9\%) and latent Tb in three patients (8.8\%).

\footnotetext{
* Correspondence: roland.elling@uniklinik-freiburg.de

${ }^{\dagger}$ Anne Geweniger and Ales Janda contributed equally to this work.

'Department of Pediatrics and Adolescent Medicine, University Medical

Center, Medical Faculty, University of Freiburg, Freiburg, Germany

Institute for Immunodeficiency, Center for Chronic Immunodeficiency,

University Medical Center, Faculty of Medicine, University of Freiburg,

Freiburg, Germany

Full list of author information is available at the end of the article
}

C C The Author(s). 2021 Open Access This article is licensed under a Creative Commons Attribution 4.0 International License, which permits use, sharing, adaptation, distribution and reproduction in any medium or format, as long as you give appropriate credit to the original author(s) and the source, provide a link to the Creative Commons licence, and indicate if changes were made. The images or other third party material in this article are included in the article's Creative Commons licence, unless indicated otherwise in a credit line to the material. If material is not included in the article's Creative Commons licence and your intended use is not permitted by statutory regulation or exceeds the permitted use, you will need to obtain permission directly from the copyright holder. To view a copy of this licence, visit http://creativecommons.org/licenses/by/4.0/ The Creative Commons Public Domain Dedication waiver (http://creativecommons.org/publicdomain/zero/1.0/) applies to the data made available in this article, unless otherwise stated in a credit line to the data. 
Conclusions: EBUS-TBNA is a sensitive and safe method with high diagnostic yield in the evaluation of pediatric patients with mediastinal pathology and suspected $\mathrm{Tb}$.

Keywords: Tuberculosis, Diagnostics, Children, Adolescents, Refugee minor, Unaccompanied, Migrants, Refugees, Mediastinal lymphadenopathy, Endobronchial ultrasound-guided transbronchial needle aspiration (EBUS-TBNA)

\section{Background}

The global burden of infections with $M$. tuberculosis $(\mathrm{MTb})$ remains high [1]. Furthermore, in the European Union (EU), MTb infections constitute a substantial public health issue [1]. Although $\mathrm{Tb}$ incidence in Germany was at a stable, low level in the years prior to 2013, a significant increase in $\mathrm{Tb}$ was seen thereafter, with numbers peaking in 2016 [2]. Largely, this rise was driven by the increase of migrants seeking asylum in Germany during this period. As in many other lowincidence countries, $\mathrm{Tb}$ incidence in Germany reflects international migration dynamics: in $2018,69.8 \%$ of newly diagnosed $\mathrm{Tb}$ patients in Germany were foreignborn. This translates to an incidence approximately 18 times higher among foreign nationals than among German citizens (37.3 vs. 2.1 cases per 100,000 population, respectively). Patients with a migration background were of younger in age as compared to Germans (age median 28 vs. 59 years). For patients with or without migration background, the pulmonary $\mathrm{Tb}$ form prevailed (72.9\%) with a low detection rate of multiple drug resistance (3.1\%; MDR) [2].

In children, $\mathrm{Tb}$ diagnostics are limited both by the lower performance of immunodiagnostic tests, such as the interferon-gamma-release assays (IGRA), and by the low yield of microbiological cultures, due to the paucibacillary nature of the disease [3]. In adolescents, a bacteriological confirmation of pulmonary tuberculosis with positive smear, PCR or culture can be obtained more frequently. However, paucibacillary disease remains a common finding [4]. For several additional reasons, refugees with suspected tuberculosis represent a particularly challenging patient cohort for $\mathrm{Tb}$ diagnostics. First, the $\mathrm{Tb}$ index patient, (and therefore the drug sensitivity of the infectious MTb), usually is unknown. Second, Tb symptoms, which are often non-specific in children, are even more difficult to elicit due to a variety of factors: language barriers and absence of patient history, as well as the manifestation of symptoms such as weight loss, which may directly result from the poor circumstances of the patient's migration [5]. Third, empirical Tb treatment based upon mycobacterial resistance patterns in the country of origin is not reliable, because the infection may have occurred in one of the transit countries on the migration route. Fourth, in refugee centers visited by the URMs on their migration route, a significant proportion of patients undergo incomplete treatment $[6,7]$.
Altogether, these factors underline the utmost importance of culture confirmation of suspected Tb. This should include drug sensitivity testing (DST) for especially vulnerable minor refugees entering the EU.

Among adults, endobronchial ultrasound-guided transbronchial needle aspiration (EBUS-TBNA) has emerged as a valuable procedure for the culture confirmation of suspected MTb intrathoracic lymphadenopathy. This minimally invasive technique allows for ultrasound-guided direct sampling of intrathoracic lymph nodes and it has been shown to increase the sensitivity and culture yield among adult patients with pulmonary $\mathrm{Tb}$ [8-11]. However, there is only limited information regarding the utility and safety of EBUSTBNA in children and adolescents for $\mathrm{Tb}$ diagnostics [12-15]. Because many pediatric and adolescent Tb patients initially present with isolated hilar lymphadenopathy and without pulmonary infiltrates [3], sampling techniques such as collection of induced sputum or gastric aspirates typically provide only a low yield of bacterial culture-positivity. The implementation of PCR-based diagnostics have significantly increased the case detection rate of suspected tuberculosis. It has been shown that the pooled sensitivity of GeneXpert in children reaches $62 \%$ with a specificity of $92 \%$ (with culture as reference standard), and a $82-94 \%$ pooled sensitivity in smear positive children aged 0-4 years [16]. However, as culture remains the current diagnostic gold standard, minimal-invasive, direct sampling of enlarged lymph nodes may offer an attractive method for testing pediatric patients with suspected $\mathrm{Tb}$ in situations where DST is essential.

Here, we present the results of a retrospective cohort of 34 unaccompanied minor refugees (URM), who, over a two-year period (January 2016-July 2018), were referred to our tertiary care center for workup of suspected pulmonary $\mathrm{Tb}$ and who required related invasive diagnostic procedures. Of note, lymph node samples acquired through EBUS-TBNA had the highest yield of all analyzed specimens.

\section{Methods}

\section{Study population}

The study cohort consisted of URM referred to the University Medical Center Freiburg, Center of Pediatrics and Adolescent Medicine, between January 2016 and July 2018, for workup of suspected $\mathrm{Tb}$ following 
infectious diseases screening according to the recommendations of the German Society of Pediatric Infectious Diseases (DGPI), the German Society of Tropical Pediatrics and International Child Health (GTP) and the German Professional Association of Pediatricians (BVKJ) [17]. The patients were retrospectively identified through a standardized review of electronic health records. Inclusion criteria were age $\geq 12$ years, a positive IGRA (either enzyme-linked-immuno-spot assay [Tb ELISpot], or QuantiFERON-TB ${ }^{\circ}$ Gold Plus [QFT]) or tuberculin skin test (TST), plus either clinical symptoms suggestive of $\mathrm{Tb}$ (cough $>3$ weeks, bloody sputum, weight loss or night sweats) or abnormal radiographic findings. In addition, all patients included underwent an invasive diagnostic workup through bronchoalveolar lavage BAL, along with either pleura fluid sampling and biopsy, bronchoscopy or EBUS-TBNA. EBUS-TBNA was performed when nonivasive sampling methods were negative, and when imaging studies suggested enlarged intrathoracic lymph nodes. The electronic health records review included examination of clinical symptoms at the time of presentation, history of previous $\mathrm{Tb}$ treatment and diagnostics during migration, and an inspection of anesthesia protocols for those patients who underwent EBUSTBNA.

\section{Diagnostic procedures and imaging}

Immunological tests performed included TST and IGRA, by Tb ELISpot or Quantiferon-TB Gold Assay. Imaging included chest X-ray, high-resolution computer tomography scans and magnetic resonance imaging. MR scans or CT scans were performed if chest X-ray findings were inconclusive, especially with respect to the presence of lymphadenopathy, and thereby facilitated the selection of patients suitable for EBUS-TBNA.

Microbiological samples were obtained from sputum, pleural fluid, bronchoalveolar lavage (BAL) and pleural or lymph node biopsy. For all patients admitted, the initial diagnostic procedure was to obtain a sputum sample for microscopy, culture and Xpert- unless they had been transferred from another hospital where sputum diagnostics had been performed already. If patients with lymphadenopathy were negative upon sputum diagnostics, EBUS-TBNA was performed and another sputum sample was obtained following the procedure.

EBUS-TBNA was performed using an Olympus ViziShot system (Olympus Ltd., Tokyo, Japan) equipped with an ultrasonic $7.5 \mathrm{MHz}$ longitudinal transducer. Lymph node biopsies were taken using a 21-gauge needle with 3-5 needle passes for each lymph node.

Microbiological diagnostics included microscopy with Ziehl-Neelsen stain (ZNS), mycobacterial culture and polymerase chain reaction (PCR) (GeneXpert MTB/RIF). Resistance testing was performed genotypically (Hain
GenoType MTBDRplus, GeneXpert MTB/RIF) and phenotypically (culture). In addition to microscopy and Ziehl-Neelsen stain, a mycobacterial PCR detection kit (MYCO Direct 1.7 LCD Array kit, Chipron, Berlin) was used as part of histopathological diagnostics in 17 cases.

\section{Descriptive data analysis}

Descriptive data analysis was performed using Microsoft Excel 2019.

\section{Results}

Sociodemographic characteristics and initial tuberculosis screening results

Among URM patients aged 14-17 (mean 16.0) years, 34 of 42 fulfilled the inclusion criteria. Of these, 33 were male (97.1\%) and all were of African origin. East African countries such as Somalia (13/34; 38\%), Eritrea (6/34; $18 \%)$ and Ethiopia $(5 / 34 ; 15 \%)$ were the top three countries of origin. The most common findings suggestive of $\mathrm{Tb}$ were radiological abnormalities in chest X-ray or $\mathrm{CT}$ scan (33/34; 97.1\%), such as lymphadenopathy, pulmonary infiltrates or pleural effusions, and positive IGRA (28/30; 93.3\%). Although TST was positive in all tested patients, it was only performed in nine URM (Table 1). Lymphadenopathy was the most frequent radiological finding $(27 / 34 ; 79.4 \%)$, followed by pulmonary infiltrates (24/34; 70.6\%; see table S1). Representative radiographic findings are given in the supplementary Figure 2 and radiological findings of EBUS-positive patients are displayed in supplementary table S3. Six URM (6/34; $17.6 \%)$ already had been treated for $\mathrm{Tb}$. No detailed information on the course of prior treatment was available. The diagnostic flowchart is depicted in Fig. 1.

\section{Endobronchial ultrasound-guided transbronchial needle aspiration (EBUS-TBNA)}

EBUS-TBNA was performed in 21 patients. Table S2 displays the characteristics of procedures performed for these patients. Duration of general anesthesia managed with laryngeal mask airway (LMA) ranged from 25 to 50 min, with an average time of $37.6 \mathrm{~min}$. One patient did not require general anesthesia and received sedation only. Bronchoscopy lasted from 15 to $35 \mathrm{~min}$, with an average duration of $20.7 \mathrm{~min}$. On average, one lymph node was punctured, and five samples obtained. Fourteen of the 21 samples tested positive for MTb. No complications occurred during the procedures.

\section{Microbiological diagnostics}

The microbiological sampling techniques in patients with suspected $\mathrm{Tb}$ are described in Fig. 1. Table 2 shows the microbiological test results. A confirmation of MTb was achieved in $73.5 \%$ of patients $(25 / 34)$. PCR diagnostics performed best, with 24 out 34 specimens proving 
Table 1 Initial tuberculosis diagnostics

\begin{tabular}{lllll}
\hline & n performed & n positive & n negative & \% \\
\hline Chest X-ray or CT-scan abnormalities & 34 & 33 & 1 & 97.1 \\
$\quad$ Chest X-ray only & 12 & 12 & 0 & 100 \\
Chest CT-scan & 22 & 21 & 1 & 95.5 \\
Positive TST & 9 & 9 & 0 & 100.0 \\
Positive QFT & 19 & 18 & 1 & 94.7 \\
Positive ELISpot & 12 & 10 & 2 & 83.3
\end{tabular}

Each patient tested positive in at least one immunodiagnostic test, except patient Nr. 29, who had a negative QFT. For this patient, further diagnostics were pursued based upon typical radiological findings. In the end, this patient was diagnosed with TB based upon a positive MTb culture from pleural effusion. Three patients (Nr. 18, 22, 25) tested positive in two tests. In two patients (Nr. 5 and 26), the test results were incongruent. Details on clinical and radiologic characteristics of all patients included are displayed in Table S1. Percentage figures in the Table 1 are rounded

Abbreviations: ELISpot enzyme-linked-immuno-spot assay, HR-CT high-resolution computer tomography, QFT QuantiFERON-TB ${ }^{\otimes}$ Gold Plus, MTb M. tuberculosis,

TST tuberculin skin test

\begin{tabular}{|c|c|c|}
\hline \multicolumn{3}{|c|}{$\begin{array}{l}\text { URM with suspected tuberculosis } \\
\qquad n=34\end{array}$} \\
\hline & & \\
\hline \multicolumn{3}{|c|}{ Immunodiagnostics } \\
\hline $\begin{array}{c}\text { TST } \\
n=9 \\
(26.5 \%)\end{array}$ & $\begin{array}{c}\text { ELISpot } \\
n=12 \\
(35.3 \%)\end{array}$ & $\begin{array}{c}\text { QFT } \\
n=19 \\
(55.9 \%)\end{array}$ \\
\hline \multicolumn{3}{|c|}{ Imaging } \\
\hline $\begin{array}{c}\text { CXR } \\
\mathrm{n}=33 \\
(97.1 \%)\end{array}$ & $\begin{array}{c}\mathrm{CT} \\
\mathrm{n}=22 \\
(64.7 \%)\end{array}$ & $\begin{array}{c}\text { MRT } \\
n=2 \\
(5.9 \%)\end{array}$ \\
\hline \multicolumn{3}{|c|}{ Microbiological sampling } \\
\hline $\begin{array}{l}\text { Sputum } \\
\mathrm{n}=32 \\
(94.1 \%)\end{array}$ & $\begin{array}{c}\text { Pleura } \\
\text { fluid or biopsy } \\
n=5 \text { and } 4 \\
(14.7 \% ; 11.8 \%)\end{array}$ & $\begin{array}{c}\text { Bronchoscopy } \\
n=33 \\
(97.1 \%)\end{array}$ \\
\hline & & $\downarrow$ \\
\hline \multicolumn{3}{|c|}{ Bronchoscopy } \\
\hline $\begin{array}{c}\mathrm{BAL} \\
\mathrm{n}=33 \\
(97.1 \%)\end{array}$ & $\begin{array}{c}\text { Biopsy (unguided) } \\
\mathrm{n}=2 \\
(5.9 \%)\end{array}$ & $\begin{array}{c}\text { EBUS-TBNA } \\
n=21 \\
(61.8 \%)\end{array}$ \\
\hline
\end{tabular}

Fig. 1 Diagnostic flowchart; TST: Tuberculin skin test, ELISpot: Enzyme-linked-immuno-spot assay, QFT: QuantiFERON-TB® Gold Plus assay, CXR: chest radiograph, CT: computer tomography, MRT: Magnetic resonance tomography, BAL: Brochoalveolar lavage, EBUS-TBNA: Endobronchial ultrasound-guided transbronchial needle aspiration 
Table 2 Results of microbiological assays ( $N=34)$

\begin{tabular}{|c|c|c|c|c|c|c|c|c|c|}
\hline \multirow[t]{3}{*}{ Type of sampling } & \multirow{3}{*}{$\begin{array}{l}\text { Number of tested patients } \\
\mathrm{n}\end{array}$} & \multicolumn{6}{|c|}{$\begin{array}{l}\text { Sensitivity of particular MTb detection } \\
\text { assay }\end{array}$} & \multicolumn{2}{|c|}{$\begin{array}{l}\text { Aggregate of MTb } \\
\text { positivity (per sample } \\
\text { type) }\end{array}$} \\
\hline & & \multicolumn{2}{|c|}{ Microscopy $^{\mathbf{b}}$} & \multicolumn{2}{|c|}{ Culture } & \multicolumn{2}{|c|}{ PCR } & \multirow[b]{2}{*}{$\mathbf{n}$} & \multirow[b]{2}{*}{$\%$} \\
\hline & & $\mathrm{n}$ & $\%$ & $n$ & $\%$ & $n$ & $\%$ & & \\
\hline Sputum & 32 & 0 & $0.0 \%$ & 7 & $21.9 \%$ & 6 & $18.8 \%$ & 9 & $28.1 \%$ \\
\hline BAL fluid & 33 & 3 & $9.1 \%$ & 8 & $24.2 \%$ & 9 & $27.3 \%$ & 12 & $36.4 \%$ \\
\hline LN Biopsy ${ }^{a}$ & 23 & 2 & $8.7 \%$ & 9 & $39.1 \%$ & 15 & $65.2 \%$ & 16 & $69.6 \%$ \\
\hline Pleural effusion/-biopsy & 8 & 2 & $25.0 \%$ & 3 & $37.5 \%$ & 4 & $50.0 \%$ & 6 & $75.0 \%$ \\
\hline Aggregate of MTb positivity (per type of assay) & 34 & 5 & $14.7 \%$ & 19 & $55.9 \%$ & 24 & $70.6 \%$ & 25 & $73.5 \%$ \\
\hline
\end{tabular}

The aggregates in the vertical column represent the diagnostic yield obtained through the respective sample type. The aggregates in the horizontal column represent the diagnostic yield of a particular MTb detection assay across all sample types. Some samples showed positivity in more than one test. This is accounted for in the aggregate numbers. Additionally, in one patient, more than one tissue sample was able to be tested. ${ }^{\mathrm{a}} 21 \mathrm{LN}$ biopsies were obtained by EBUS-TBNA, two by regular bronchoscopy. 'Detection of acid-fast bacilli with Ziehl-Neelsen staining.

Abbreviations BAL bronchoalveolar lavage, EBUS-TBNA endobronchial ultrasound-guided transbronchial needle aspiration, $L N$ lymph node, $P C R$ polymerase chain reaction, $M T b M$. tuberculosis

positive (70.6\%). Culture-confirmation was achieved in $55.9 \%(19 / 34)$ of patients. Sputum culture, the current gold standard, was positive in only seven out of 32 cases (21.9\%). Of all samples obtained, biopsies from lymph nodes or pleura showed the highest sensitivity: 69.6\% (16 of 23 ) and $75.0 \%$ (6 of 8).

Following EBUS-TBNA, a total of 14 patients tested positive for MTb. In these patients, BAL by any method (microscopy, culture, PCR) was positive in 6/14. PCR only from BAL was positive in $3 / 14$ patients, illustrating the additional diagnostic benefit of EBUS-TBNA over BAL alone.

Resistance testing was performed in 32 of 34 cases (94.1\%), with two cases receiving culture testing only. Culture and genotypic test results matched in $80 \%$ of cases (24 of 30). Of the 25 patients for whom an infection with MTb was microbiologically confirmed, five patients showed mono- or multidrug resistance (MDR). Isoniazid monoresistance was documented in two patients, one from Somalia and one from Eritrea. In one patient from Somalia, streptomycin monoresistance was found. In two patients from Somalia, MDR resistance was discovered. One of the two patients diagnosed with MDR-Tb already had received $\mathrm{Tb}$ treatment along the migration route, prior to admission to our hospital.

\section{Lymph node histology}

Histological analysis of lymph node biopsies was available from 21 patients (2/2 non-EBUS guided biopsies, 19/21 EBUS-guided biopsies). From 2/21 patients (9.5\%) undergoing EBUS, the material was not sufficient for detailed histological analysis (Table 3). The histological analysis of the lymph node specimens revealed granuloma formation in 14/21 (66.7\%) samples. Of note, from the 7 specimens without detectable lymph node granulomas and negative Ziehl-Neelsen staining, a definite diagnosis of tuberculosis could be established through
PCR and culture in 6/7 specimens, one sample was only positive by PCR.

\section{Final diagnosis}

Pulmonary Tb was diagnosed in 29 patients (85.4\%), miliary $\mathrm{Tb}$ in two patients $(5.9 \%)$ and latent $\mathrm{Tb}$ in three patients $(8.8 \%)$. The most common clinical symptoms were weight loss, chronic cough and dyspnea (44.4, 40.6 and $21.7 \%$ respectively; Table $\mathrm{S} 1$ ).

\section{Discussion}

Among children and adolescents, diagnostic yields from microbiologic techniques from bronchoalveolar lavage and sputum provide only a low yield. As a result, many patients have to be treated with empirical antituberculous drugs. EBUS-TBNA is a minimally invasive, diagnostic procedure with relatively high diagnostic yield. Among adults, it is broadly used [18, 19], but in the pediatric population it is rarely applied [15].

The first case of EBUS-TBNA in a 13-year-old male child with sarcoidosis was published in 2009 [20]. To date, four larger, retrospective studies evaluating EBUSTBNA use in the diagnosis of mediastinal lymphadenopathy, including $\mathrm{Tb}$ in children, have been published [12, $14,21,22]$. Of note, in most of these studies, EBUSTBNA was not performed for specific Tb diagnostics, but for the workup of enlarged mediastinal lymph nodes of non-infectious origin. Additionally, individual case

Table 3 Histopathological findings from lymph node biopsies

\begin{tabular}{lll}
\hline Histopathological findings & $\mathbf{n}$ & $\%$ \\
\hline Granuloma formation & $14 / 21$ & 66.7 \\
Necrosis & $11 / 21$ & 52.4 \\
Positive Ziehl-Neelsen stain & $4 / 14$ & 28.6 \\
Detection of M.tuberculosis DNA in tissue $^{\mathrm{a}}$ & $9 / 15$ & $60.0 \%$ \\
\hline
\end{tabular}

${ }^{a}$ kit: MYCO Direct 1.7 LCD Array Kit 
reports have documented its utility in $\mathrm{Tb}$ diagnostics for children and adolescents [13, 23]. Because the use of EBUS-TBNA is limited by the size of airway diameter, the number of children under 12 years old who have been reported to have received EBUS-TBNA is low. In younger patients, an alternative method that does not impede ventilation, e.g., endoscopic ultrasound bronchoscope-guided fine needle aspiration (EUS-BFNA), needs to be applied [12, 14, 21, 24]. In the literature, the youngest patient described for whom TBNA with a $4 \mathrm{~mm}$ scope has been used to evaluate mediastinal lymphadenopathy was a nine-month-old infant [22]. Because the patients in our study were $\geq 14$ years of age, there was no anatomical hindrance to using EBUSTBNA.

Out of the 34 URM eligible for our study, EBUSTBNA was perfomed in 21 patients. The diagnostic yield of the fine-needle aspiration $(14 / 21 ; 66.7 \%)$ was higher as compared to other pediatric studies (36.0-56.9\%) [12, $14,21,22]$, and also as compared to the EBUS-TBNA diagnostic yield reported in adult patients (64.6-96.6\%) [19], as well as to meta-analysis with pooled sensitivity of the procedure of $80 \%$ [25]. Of the $14 / 21$ patients who were positive through EBUS, culture was positive in 9/ 14 samples (64.3\%), PCR in $13 / 14$ samples (92.9\%) and microscopy in $1 / 14$ samples (7.1\%). This finding illustrates that at least genomic material of mycobacteria is present in the great majority of enlarged intrathoracic lymph nodes. However, the lower rate of culture positivity compared to PCR detection suggests that lymph node enlargement may persist after successful immunological clearance of replication competent mycobacteria from a lymph node. Of note, our PCR detection rate of $27 \%$ from BAL samples was lower than in published pediatric cohorts, reporting a sensitivity of up to $78 \%[26,27]$, We hypothesize this may be due to the mostly paucibacillary disease of our patients, where the majority of pathogen burden is contained within lymph nodes. Overall, EBUS was the only positive diagnostic method via PCR or culture in 7/14 patients, illustrating the benefit of this diagnostic approach.

In our evaluation of several $\mathrm{Tb}$ detection methods, the molecular genetic approach using PCR performed best. PCR provided a positivity of $70.6 \%$ (24/34), followed by culture proof $(19 / 34 ; 55.9 \%)$ and detection with ZNS (5/ $34 ; 14.7 \%)$. These findings correspond to already published data for adults [10, 19]. Using a combination of invasive and non-invasive diagnostic approaches allowed us to detect $\mathrm{MTb}$ and evaluate drug sensitivity in $93.5 \%$ (29/31) active Tb cases. Importantly, a molecular or cultural diagnosis of $\mathrm{Tb}$ was possible in 6/7 lymph note specimens without detectable granulomas and a negative Ziehl-Nehlsen staining, illustrating the insufficient negative predictive value of negative histology.
Our detection of drug resistance in $17.2 \%$ (5/29) of patients with active $\mathrm{Tb}$ (monoresistance in 10.3\% (3/29); MDR in $6.9 \%(2 / 29)$ patients) underlines the importance of sample acquisition for drug sensitivity testing. This drug resistance level is higher than has been reported elsewhere (MDR in 3.3.\% pediatric and 5.0\% adult patients, respectively) [10, 21].

Contrary to study of Gulla et al. [21], where approximately one-fourth of patients were treated with empiric anti-tuberculous medication, none of our patients received any tuberculostatic drugs during the period of microbial sampling. This fact may have contributed to the higher diagnostic yield, especially with respect to culture-positivity.

Six of our patients had a history of tuberculostatic treatment. In two of them, MTb detection failed. For another two, MTb could be detected in sputum (1 x ZNS and PCR; 1 x PCR) and in pleural effusion or BAL (PCR). In one patient, MTb was found in BAL (ZNS, culture, PCR) and in pleural effusion (ZNS and PCR). In the last patient, MTb detection was only possible in a LN sample gained via EBUS-TBNA (PCR).

In our cohort, no complications occurred following EBUS-TBNA. Others have reported rare (i.e., sepsis, pneumothorax, significant hemorrhage) or minor (transient hypoxemia, hypotension or tachycardia, and excessive coughing) complications [10, 12, 14, 21, 28]. EBUSTBNA is considered to be a safe diagnostic procedure in adults as well as in pediatric patients. Nevertheless, the procedure requires additional training and experience. Due to the low number of pediatric $\mathrm{Tb}$ cases pediatric pulmonologists may see, such experience may be difficult to obtain [29]. Our team included both pediatric and adult pneumologists.

\section{Study limitations}

Due to its retrospective design, a significant amount of clinical data was missing. Furthermore, the selected URM cohort we describe was in a particular geographic area in Germany. For these reasons, the epidemiological data cannot be extrapolated to be applicable to all URM in Germany or Europe. In addition, our sample only includes adolescents. This further limits the generalizability of our findings.

Despite its performance, another important limitation of EBUS-TBNA is the requirement of costly endoscopy equipment and adequate training possibilities of pediatric pulmonologists, which is especially limiting in resource-poor settings with a high $\mathrm{Tb}$ disease burden.

\section{Conclusion}

Our study demonstrates the utility, safety and feasibility of EBUS-TBNA in a relatively large pediatric population. Its high diagnostic yield may facilitate more accurate 
diagnostic follow-up for patients with mediastinal lymphadenopathy and suspected $\mathrm{Tb}$. It also may help physicians more clearly identify when tuberculostatic therapy is needed.

\section{Abbreviations}

BAL: Bronchoalveolar lavage; BVKJ: German Professional Association of Pediatricians; DST: Drug sensitivity testing; DGPI: German Society of Pediatric Infectious Disease; EBUS-TBNA: Endobronchial ultrasound-guided transbronchial needle aspiration; EUS-B-FNA: Endoscopic ultrasound bronchoscopeguided fine needle aspiration; ELISpot: Enzyme-linked-immuno-spot assay; EU: European Union; GTP: German Society of Tropical Pediatrics and International Child Health; IGRA: Interferon-gamma-release assay; HRCT: Highresolution computer tomography; LN: Lymph node; MRT: Magnetic resonance tomography; MDR: Multi-drug-resistance; MTb: M. tuberculosis; QFT: QuantiFERON-TB ${ }^{\oplus}$ Gold Plus assay; PCR: Polymerase chain reaction; Tb: Tuberculosis; TST: Tuberculin skin test; URM: Unaccompanied refugee minor; ZNS: Ziehl-Neelsen stain

\section{Supplementary Information}

The online version contains supplementary material available at https://doi. org/10.1186/s12879-021-06413-z.

Additional file 1: Table S1. Clinical and radiologic characteristics of all patients $(n=34)$. Table S2. Technical details on the EBUS-TBNA procedures $(n=21)$. Table S3. Radiological findings of patients undergoing EBUS $(n=14)$.

Additional file 2. Representative radiographic findings.

\section{Acknowledgements}

We thank Natalie Diffloth for her English language proof-reading of the manuscript.

\section{Authors' contributions}

$\mathrm{MH}, \mathrm{PH}$ and RE designed the study. AG and KE collected data. AG and AJ conducted data analysis. AG, AJ, MH, RE wrote the manuscript. RF, CVK, HF identified the patients and provided clinical data. ME and CM performed EBUS-TBNA. All authors contributed to review and revision of the report and have seen and approved the final version of manuscript. AG and AJ contributed equally to this work.

\section{Funding}

The authors received no specific funding for this work. Open Access funding enabled and organized by Projekt DEAL.

\section{Availability of data and materials}

The datasets used and/or analysed during the current study are available from the corresponding author on reasonable request.

\section{Declarations}

Ethics approval and consent to participate

A legal guardian was assigned to each URM by the municipality that provided written consent for the required diagnostic procedures and therapeutic recommendations. Because of the high rate of URM illiteracy, formal written consent was not always obtained from the patients.

Diagnostics and therapy were discussed with the patients through support of a professional interpreter, or else by someone speaking a shared language when a professional interpreter was not readily available. Inpatient and outpatient treatment were made possible through government-provided health insurance. This allowed URMs to obtain healthcare comparable to that received by nonimmigrant children in Germany. The study protocol was approved by the ethics committee of the University of Freiburg as a noninterventional study (No. 340/18).

\section{Consent for publication}

N/A.

\section{Competing interests}

The authors declare that they have no competing interests.

\section{Author details}

${ }^{1}$ Department of Pediatrics and Adolescent Medicine, University Medical Center, Medical Faculty, University of Freiburg, Freiburg, Germany.

${ }^{2}$ Department of Pediatrics and Adolescent Medicine, University Medical Center UIm, Ulm, Germany. ${ }^{3}$ Practice for Pediatric and Adolescent Medicine, Freiburg, Germany. ${ }^{4}$ St. Elisabethen Hospital Lörrach, Lörrach, Germany. ${ }^{5}$ Department of Thoracic Surgery, University Medical Center, Medical Faculty, University of Freiburg, Freiburg, Germany. ${ }^{6}$ Institute for Immunodeficiency, Center for Chronic Immunodeficiency, University Medical Center, Faculty of Medicine, University of Freiburg, Freiburg, Germany. ${ }^{7}$ Berta Ottenstein Program, University Medical Center, Medical Faculty, University of Freiburg, Freiburg, Germany.

Received: 10 September 2020 Accepted: 25 June 2021

Published online: 14 September 2021

\section{References}

1. World health organisation (WHO). Global tuberculosis report 2019. Geneva: World health organisation (WHO); 2019.

2. Robert Koch-Institut. Bericht zur Epidemiologie der Tuberkulose in Deutschland für 2018; 2019. https://doi.org/10.17886/rkipubl-2015-005.

3. Perez-Velez CM, Marais BJ. Tuberculosis in children. N Engl J Med. 2012;367: 348-61. https://doi.org/10.1056/NEJMra1008049.

4. Snow KJ, Cruz AT, Seddon JA, Ferrand RA, Chaing SS, Hughes JA, et al. Adolescent tuberculosis. Lancet Child Adolesc Health. 2020:4(1):68-79. https://doi.org/10.1016/\$2352-4642(19)30337-2.

5. Janda A, Eder K, Fressle R, Geweniger A, Diffloth N, Heeg M, et al. Comprehensive infectious disease screening in a cohort of unaccompanied refugee minors in Germany from 2016 to 2017: a cross-sectional study. PLoS Med. 2020;17:e1003076. https://doi.org/10.1371/journal.pmed.1003076.

6. Kuehne A, Hauer B, Brodhun B, Haas W, Fiebig L. Screening and prevention of infectious diseases in newly arrived migrants. Find and treat or find and lose? Tuberculosis treatment outcomes among screened newly arrived asylum seekers in Germany 2002 to 2014. Eurosurveillance. 2018;23. https:// doi.org/10.2807/1560-7917.ES.2018.23.11.17-00042.

7. Alsdurf H, Hill PC, Matteelli A, Getahun H, Menzies D. The cascade of care in diagnosis and treatment of latent tuberculosis infection: a systematic review and meta-analysis. Lancet Infect Dis. 2016;16:1269-78. https://doi.org/10.101 6/S1473-3099(16)30216-X.

8. Sun J, Teng J, Yang H, Li Z, Zhang J, Zhao H, et al. Endobronchial ultrasound-guided transbronchial needle aspiration in diagnosing intrathoracic tuberculosis. Ann Thorac Surg. 2013;96:2021-7. https://doi. org/10.1016/j.athoracsur.2013.07.005.

9. Hassan T, McLaughlin AM, O'Connell F, Gibbons N, Nicholson S, Keane J. EBUS-TBNA performs well in the diagnosis of isolated thoracic tuberculous lymphadenopathy. Am J Respir Crit Care Med. 2011;183:136-7. https://doi. org/10.1164/ajrccm.183.1.136

10. Navani N, Molyneaux PL, Breen RA, Connell DW, Jepson A, Nankivell M, et al. Utility of endobronchial ultrasound-guided transbronchial needle aspiration in patients with tuberculous intrathoracic lymphadenopathy: a multicentre study. Thorax. 2011;66:889-93. https://doi.org/10.1136/thora xjn-2011-200063.

11. Gupta N, Muthu V, Agarwal R, Dhooria S. Role of EBUS-TBNA in the diagnosis of tuberculosis and sarcoidosis. J Cytol. 2019;36:128-30. https:// doi.org/10.4103/JOC.JOC_150_18.

12. Dhooria S, Madan K, Pattabhiraman V, Sehgal IS, Mehta R, Vishwanath G, et al. A multicenter study on the utility and safety of EBUS-TBNA and EUS-BFNA in children. Pediatr Pulmonol. 2016;51:1031-9. https://doi.org/10.1002/ ppul.23415.

13. Madan K, Ayub II, Mohan A, Jain D, Guleria R, Kabra SK. Endobronchial ultrasound-guided Transbronchial needle aspiration (EBUS-TBNA) in Mediastinal lymphadenopathy. Indian J Pediatr. 2015;82:378-80. https://doi. org/10.1007/s12098-014-1665-3.

14. Gilbert CR, Chen A, Akulian JA, Lee HJ, Wahidi M, Argento AC, et al. The use of convex probe endobronchial ultrasound-guided transbronchial needle aspiration in a pediatric population: a multicenter study. Pediatr Pulmonol. 2014;49:807-15. https://doi.org/10.1002/ppul.22887. 
15. Shanthikumar S, Steinfort DP, Ranganathan S. Interventional bronchoscopy in children: planning the path ahead. Pediatr Pulmonol. 2020;55:288-91. https://doi.org/10.1002/ppul.24596.

16. Detjen AK, DiNardo AR, Leyden J, Steingart KR, Menzies D, Schiller I, et al. Xpert MTB/RIF assay for the diagnosis of pulmonary tuberculosis in children: a systematic review and meta-analysis. Lancet Respir Med. 2015;3(6):451-61. https://doi.org/10.1016/S2213-2600(15)00095-8.

17. Pfeil J, Kobbe R, Trapp S, Kitz C, Hufnagel M. Recommendations for the diagnosis and prevention of infectious diseases in pediatric and adolescent refugees in Germany. Monatsschr Kinderheilkd. 2015;163:1269-86. https:// doi.org/10.1007/s00112-015-0003-9.

18. Silvestri GA, Gonzalez AV, Jantz MA, Margolis ML, Gould MK, Tanoue LT, et al. Diagnosis and management of Lung Cancer, 3rd ed: ACCP guidelines. Chest. 2013;143:e211S-50S. https://doi.org/10.1378/chest.1435S1.

19. Aljohaney AA. Role of convex probe endobronchial ultrasound in the diagnosis and treatment of nonmalignant diseases. Pulm Med. 2019;2019. https://doi.org/10.1155/2019/6838439.

20. Wurzel DF, Steinfort DP, Massie J, Ryan MM, Irving LB, Ranganathan SC. Paralysis and a perihilar protuberance: an unusual presentation of sarcoidosis in a child. Pediatr Pulmonol. 2009;44:410-4. https://doi.org/10.1 002/ppul.20979.

21. Gulla KM, Gunathilaka G, Jat KR, Sankar J, Karan M, Lodha R, et al. Utility and safety of endobronchial ultrasound-guided transbronchial needle aspiration and endoscopic ultrasound with an echobronchoscope-guided fine needle aspiration in children with mediastinal pathology. Pediatr Pulmonol. 2019; 54:881-5. https://doi.org/10.1002/ppul.24313.

22. Goussard P, Gie RP, Kling S, Nel ED, Louw M, Schubert PT, et al. The diagnostic value and safety of transbronchial needle aspiration biopsy in children with mediastinal lymphadenopathy. Pediatr Pulmonol. 2010;45: 1173-9. https://doi.org/10.1002/ppul.21303.

23. Kim K, Lee K, Kim Y. The first pediatric case of intrathoracic tuberculosis lymphadenitis diagnosed by endobroncial ultrasound guided needle aspiration. Korean J Pediatr Infect Dis. 2013:186-9.

24. Madan K, Garg P, Kabra SK, Mohan A, Guleria R. Transesophageal Bronchoscopic ultrasound-guided fine-needle aspiration (EUS-B-FNA) in a 3year-old child. J Bronchol Interv Pulmonol. 2015;22:347-50. https://doi.org/1 0.1097/LBR.0000000000000169.

25. Ye W, Zhang R, Xu X, Liu Y, Ying K. Diagnostic efficacy and safety of Endobronchial ultrasound-guided Transbronchial needle aspiration in Intrathoracic tuberculosis: a Meta-analysis. J Ultrasound Med. 2015;34:164550. https://doi.org/10.7863/ultra.15.14.06017.

26. Sun L, Qi X, Liu F, Wu X, Yin Q, Guo Y, et al. A test for more accurate diagnosis of pulmonary tuberculosis. Pediatrics. 2019;144(5):e20190262. https://doi.org/10.1542/peds.2019-0262.

27. Walters E, Goussard P, Bosch C, Hesseling AC, Gie RP. GeneXpert MTB/RIF on bronchoalveolar lavage samples in children with suspected complicated intrathoracic tuberculosis: a pilot study. Pediatr Pulmonol. 2014;49(11):11337. https://doi.org/10.1002/ppul.22970.

28. Eapen GA, Shah AM, Lei X, Jimenez CA, Morice RC, Yarmus L, et al. Complications, consequences, and practice patterns of endobronchial ultrasound-guided transbronchial needle aspiration: results of the AQulRE registry. Chest. 2013;143:1044-53. https://doi.org/10.1378/chest.12-0350.

29. Burks AC, Vece T, Akulian J. Should endoscopic ultrasound-guided biopsies for mediastinal abnormalities be performed by pediatric pulmonologists? Pediatr Pulmonol. 2019;54:1647-9. https://doi.org/10.1002/ppul.24472.

\section{Publisher's Note}

Springer Nature remains neutral with regard to jurisdictional claims in published maps and institutional affiliations.

Ready to submit your research? Choose BMC and benefit from:

- fast, convenient online submission

- thorough peer review by experienced researchers in your field

- rapid publication on acceptance

- support for research data, including large and complex data types

- gold Open Access which fosters wider collaboration and increased citations

- maximum visibility for your research: over $100 \mathrm{M}$ website views per year

At BMC, research is always in progress.

Learn more biomedcentral.com/submissions 